\title{
EVALUATION OF TAENIA SAGINATA METACESTODES ANTIGENIC FRACTIONS FOR THE DIAGNOSIS OF HUMAN NEUROCYSTICERCOSIS (ABSTRACT)*. THESIS. UBERLÂNDIA, 2008.
}

\section{HELIANA BATISTA DE OLIVEIRA**}

The application of Taenia saginata metacestodes as heterologous antigen is an important alternative for neurocysticercosis (NC) serodiagnosis. The cross-reaction with Echinococcus granulosus infection occurs with homologous and heterologous antigens, and could be avoid using different methods of purification.

This study analyzed antigen fractions obtained from crude saline extract of $\mathrm{T}$. saginata metacestodes purified by affinity chromatography with the lectin jacalin, concanavalin $\mathrm{A}$ and $\mathrm{N}$-acetilglycosamin for the detection of IgG antibodies by ELISA and immunoblotting, was also analyzed the application of T. saginata metacestodes as an alternative antigen for use in ELISA and immunoblotting tests in cerebrospinal fluid (CFS) samples. Serum samples were obtained from 142 individuals: 40 were diagnosed with NC, 62 presented other parasitic diseases, including taeniasis and 40 were apparently healthy individuals. The CSF samples were obtained from 35 patients with definitive neurocysticercosis and 35 patients with other neurological disorders.

Among the antigenic fractions, the concanavalin A un- bound fraction demonstrated higher sensitivity and specificity by ELISA ( $90 \%$ and $93.1 \%$, respectively). By immunoblotting, the concanavalin unbound fraction showed $100 \%$ of sensitivity and specificity, where only serum samples from patients with NC recognized the band of 64-68 $\mathrm{kDa}$, so this antigen fraction may be used as specific antigen for diagnosis of NC. The sensitivity and specificity of ELISA using antigen obtained from T. saginata applied to CSF samples results of $100 \%$ and $94.3 \%$, respectively. The 47-52, 64-68 and $70 \mathrm{kDa}$ antigens were only recognized by CSF samples from patients with NC.

The identification of specify band of $64-68 \mathrm{kDa}$, in patients with NC using unbound concanavalina A fraction demonstrates high sensitivity and specificity in the immunodiagnosis, and indicated that T. saginata metacestodes can be used as alternative antigen for NC diagnosis using CSF samples.

Key words: neurocysticercosis, Taenia saginata, concanavalin $\mathrm{A}$, jacalin, $\mathrm{N}$-acetilglycosamin, ELISA, cerebrospinal fluid, serum, immunoblotting.

*Avaliação de frações antigênicas da Taenia saginata para o diagnóstico da neurocisticercose humana. (Resumo). Tese de Doutorado, Universidade Federal de Uberlândia (Área: Laboratório de Parasitologia, Departamento de Imunologia, Microbiologia e Parasitologia, Instituto de Ciências Biomédicas). Orientadora: Julia Maria Costa Cruz.

** Address: Avenida Pará 1720 - 38400-902 Uberlândia MG - Brasil (E-mail: costacruz@ufu.br). 